\title{
O EFEITO VINCULANTE DOS PRECEDENTES JUDICIAIS NO PROCESSO TRIBUTÁRIO ADMINISTRATIVO
}

\author{
Flávio Couto Bernardes ${ }^{1}$ \\ Rodrigo Henrique Pires ${ }^{2}$
}

\section{Resumo:}

O objetivo deste trabalho é analisar o efeito vinculante dos precedentes judiciais no Processo Tributário Administrativo. Com o advento do Novo Código de Processo Civil surgiram novas regras relativas aos efeitos dos precedentes judiciais, com a finalidade de garantir maior unicidade da jurisprudência. Ocorre que surgiram dúvidas a respeito da sua aplicação no âmbito do Processo Tributário Administrativo, já que está inserido no âmbito do Poder Executivo.

Palavras-chave: Precedentes; judiciais; tributário; administrativo; vinculação

\section{THE BINDING EFFECT OF JUDICIAL PRECEDENTS ON THE ADMINISTRATIVE TAX PROCEEDINGS}

\begin{abstract}
:
The purpose of this paper is to analyze the binding effect of judicial precedents on the Administrative Tax Proceedings. With the advent of the New Code of Civil Procedure, new rules emerged regarding the effects of judicial precedents, in order to ensure greater unity of jurisprudence. Doubts have arisen as to its application under the Administrative Tax Procedure, as it is within the scope of the Executive Branch.
\end{abstract}

Keywords: Precedents; judicial proceedings; tributary; administrative; binding

\section{Introdução}

Uma das pretensões mais básicas do Direito é regular os atos e atitudes, solucionando os conflitos existentes entre os jurisdicionados ${ }^{3}$. Fazendo um corte temporal na

\footnotetext{
${ }^{1}$ Advogado. Mestre e Doutor em Direito Tributário pela Universidade Federal de Minas Gerais. Endereço: flavio.bernardes@bernardesadvogados.adv.br

${ }^{2}$ Advogado. Mestrando em Direito Público pela Pontifícia Universidade Católica de Minas Gerais. Endereço: rodrigohpires@gmail.com

${ }^{3}$ Uma importante contribuição nesse sentido é dada por Flávio Couto Bernardes, em sua tese doutoral, que destaca o papel garantidor do Poder Judiciário no que se refere à estabilidade do sistema do direito, especialmente no que tange à interpretação normativa. Nesse sentido, o autor aponta que "cabe ao juiz apenas e tão somente aplicar a lei, evitando realizar juízos valorativos quanto à sua opinião de como o direito positivo deveria ser, o que implicaria na realização de alterações legislativas através do uso indevido de sua função jurisdicional, em verdadeira quebra do princípio democrático da separação dos poderes do Estado. Se a norma estabelece determinado procedimento, não cabe ao seu aplicador arguir se ele é necessário ou não, pois esta decisão é exclusiva do povo ao dispor sobre as regras que deve seguir. Não se trata de "positivismo" exagerado
} 
história brasileira, especificamente com o advento da Constituição de 1988, passaram a ser expressamente previstos inúmeros direitos sociais individuais e coletivos, principalmente considerando o momento vivido antes da sua promulgação.

Visando tutelar todos os direitos nela previstos, foi necessário aumentar a gama de ações judiciais manejáveis. Somente assim seria possível criar os instrumentos necessários para viabilizar a apreciação, pelo Poder Judiciário, dessas lesões ou amaça de lesões aos direitos dos jurisdicionados.

Com o passar de pouco tempo, observou-se que os instrumentos até então existentes não seriam suficientes para solucionar os conflitos que surgiam, tendo em vista inúmeros fatos de cunho jurídico, social e político. A facilidade de acesso ao Poder Judiciário, bem como uma maior conscientização social, seguidas de clara ineficiência administrativa e política da própria Administração Pública, acabou resultando em inesperado aumento exponencial das demandas judiciais. Esse aumento chegou ao ponto de comprometer a própria prestação jurisdicional, dada a incapacidade do Poder Judiciário de apreciar as demandas em tempo minimamente razoável.

Essa ineficiência é demonstrada pelo denominado "Justiça em Números", elaborado pelo Conselho Nacional de Justiça. No Relatório Analítico do ano de 2018, ano-base de 2017, que trata da estrutura e grau de litigiosidade nacional, constatou-se que existem 80,1 milhões de processos em tramitação, com verificação de aumento de $0,3 \%$ em relação ao ano anterior.

Nesse mesmo documento constatou-se que houve um aumento de 18,3\% dos denominados "serviços de justiça", considerando toda a série histórica desde 2009. A taxa de congestionamento, ou seja, relativa aos feitos que estão parados aguardando julgamento, é de $72,1 \%$. Esse número demonstra que a capacidade do Poder Judiciário de promover respostas é, neste momento, insuficiente para a demanda existente.

Associado a esse quadro de multiplicação de demandas, surge também a indesejada dispersão jurisprudencial, resultante da incapacidade dos próprios órgãos responsáveis pela aplicação do direito em caráter definitivo (jurisdição) de promover orientações coerentes e consolidadas sobre a mesma matéria.

ou inútil. Se há algo de inútil é o desvirtuamento da aplicação da norma, de modo a quebrar a estabilidade e previsibilidade que se espera do ordenamento jurídico, o que, seguramente, motiva a quebra da confiança que hoje se verifica no Poder Judiciário" (2006, p. 197-198). Assim, ao funcionar como elemento estabilizador do sistema o Poder Judiciário tem a importante tarefa de controle do alcance do Poder e do arbítrio estatal, o que o faz com a processualização das expectativas normativas, que desemboca na formulação dos precedentes. 
Exatamente neste cenário que se buscou criar instrumentos no ordenamento jurídico que reduzam ou acabem com essa dispersão, sob pena de criar instabilidade em todo sistema jurídico. A proposição de soluções para a peculiar situação brasileira demanda especial atenção e estudo, sobretudo por se tratar de país que comunga da matriz do civil law, que tem como base principal a norma jurídica positivada pelo texto da lei.

Em razão disso, cada vez mais se verifica a interpenetração entre os sistemas jurídicos do civil law e do common law, cada um transcrevendo e se apropriando em seus códigos das estruturas recíprocas, sem perder a configuração original e marcante de ambos, buscando otimizar o julgamento das demandas.

Merece especial destaque o CPC/2015, que passou a prever o denominado sistema de precedentes no ordenamento jurídico brasileiro. Criou-se inúmeros instrumentos para que o Poder Judiciário possa realizar, de modo satisfatório e rápido, a prestação jurisdicional. A sistematização desse instituto jurídico se deu por meio dos artigos 926 e 927, que trataram de forma específica seus efeitos, consequências e necessidade de observação por parte dos julgadores.

Ocorre que, passados alguns anos do início de vigência do CPC/2015, passa-se a questionar sobre os efeitos vinculantes das decisões judiciais no âmbito dos Procedimentos Tributários Administrativos. O questionamento é relevante e necessário, na medida em que a Administração Pública, seja no âmbito municipal, estadual ou federal, é a maior litigante do país, assoberbando o Poder Judiciário com milhões de ações anualmente.

No âmbito do Direito Tributário inúmeros questionamentos devem ser realizados a partir do problema proposto, relativo à aplicação dos precedentes da jurisdição no âmbito dos procedimentos administrativos tributários: é razoável a continuidade de seu trâmite, com a consequente consolidação do crédito tributário, nas situações em que a orientação pela sua inconstitucionalidade/ilegalidade já foi definida pelos Tribunais Superiores; existem mecanismos no ordenamento jurídico brasileiro que permitem o encerramento desses casos no âmbito administrativo; a continuidade da cobrança viola os princípios da isonomia e da segurança jurídica.

As demandas tributárias estão intrinsicamente ligadas à análise do sistema de precedentes instituído no Brasil, especialmente por se tratar de matérias, em sua maioria, cuja discussão é exclusivamente de direito e, portanto, alcançam elevado número de contribuintes, dado o seu caráter generalizado. 
Dessa forma, o presente trabalho irá analisar, sem a pretensão de esgotar o tema, o sistema de precedentes instituído no Brasil, bem como a sua aplicabilidade no âmbito do Procedimento Tributário Administrativo. O estudo também pretende propor medidas e soluções que podem, neste momento, mitigar os impactos das demandas tributárias no sistema judiciário brasileiro.

\section{Noções básicas de precedentes judiciais}

O cenário judicial nacional historicamente se viu permeado de alta discricionariedade dos Tribunais em relação à interpretação e aplicação do direito ${ }^{4}$. Avaliando esse ambiente, constata-se que o complexo desenho constitucional e das próprias instituições permitiu um exagerado e indesejado aumento do subjetivismo no momento de atribuir sentidos que a mesma norma jurídica pode emanar.

Esse aumento de subjetividade e diversidade de sentidos para a mesma norma naturalmente causa instabilidade e inconsistência em todo o sistema normativo, causando insegurança nos jurisdicionados. Isto porque, a atividade interpretativa, de justificação e aplicação da norma jurídica por parte dos órgãos judiciais acaba por estabelecer, de modo impositivo, a interpretação normativa que deve prevalecer naquela exata moldura fática analisada. Estabelece-se, assim, um parâmetro de decidibilidade.

Esse parâmetro pode ser denominado como precedente, como afirma MARINONI: “os precedentes não são equivalentes às decisões judiciais. Eles são razões generalizáveis que podem ser identificadas a partir das decisões judiciais. O precedente é formado a partir da decisão judicial.” (2017, p. 645).

Para DIDIER, BRAGA e OLIVEIRA, precedente judicial pode ser conceituado como "a decisão judicial tomada à luz de um caso concreto, cujo núcleo essencial pode servir

\footnotetext{
${ }^{4}$ A interpretação e a aplicação do direito são fenômenos que, se não balizados pelo próprio sistema jurídico, podem acarretar inúmeros excessos em razão da alta carga de discricionariedade que podem alcançar. Nesse sentido, abre-se espaço para que as decisões judiciais comecem a pulverizar a eficácia e efetividade do direito positivo, repercutindo, até mesmo, na própria fidedignidade da doutrina. Nesse sentido, pode-se dizer que "uma decisão judicial deficiente abre brechas para que a própria dogmática jurídica seja questionada, fazendo surgir, nessa dicção, como será visto no próximo tópico, universos jurídicos sem limites para as interpretações dos magistrados e cidadãos desconfiados. Logo, no regime do sistema da civil law adotado no direito brasileiro, a jurisprudência possui o papel de uniformização da inteligência dos enunciados das normas que formam o ordenamento jurídico. Essa função jurisprudencial é, aliás, uma das formas do direito processual prestigiar, acima de tudo, a segurança jurídica" (BERNARDES; PIMENTA, 2018, p. 6).
} 
como diretriz para o julgamento posterior de casos análogos” (2010, p. 381). Segundo MARCATO, a aplicação do precedente:

\footnotetext{
poupa tempo, dificuldades e responsabilidades ao juiz e, além disso, relaciona-se estreitamente à ideia de justiça formal, pois casos análogos receberão tratamento similar, assim asseguradas a igualdade de tratamento das partes e a previsibilidade no julgamento. (2014, p. 249).
}

Constata-se que o precedente, portanto, não pode ser entendido como norma jurídica, mas sim como comando específico dotado de caráter vinculante decorrente da atividade jurisdicional. Dada a sua própria natureza, está intrinsicamente ligado ao caso concreto que resultou do seu nascimento. A partir do caso concreto e das suas especificidades, é possível retirar a denominada "razão generalizável".

Segundo LOPES FILHO, o precedente "elide o desenvolvimento de outras decisões a partir de um grau zero, evitando subjetivismo entre casos substancialmente iguais." (2016, p. 275). DIDIER, por sua vez, afirma que o precedente é composto de alguns elementos característicos mínimos, sendo eles: i) escopo fático que compreendem a controvérsia; ii) tese jurídica assentada na motivação (ratio decidendi); e iii) argumentação jurídica em torno da questão posta (2017, p. 505).

Diferentemente das normas gerais e abstratas, todo precedente tem como ponto de partida um caso concreto. Este pode ser um determinado fato, do mundo do ser, ou uma tese objetiva, de confronto de norma jurídica em face de dado parâmetro normativo, como ocorre no controle de constitucionalidade.

A ratio decidendi trata-se de verdadeira proposição do direito, explícita ou implícita, imprescindível para a própria decisão. São os fundamentos jurídicos essenciais de uma decisão judicial para resolver aquele caso concreto. É a explicitação do raciocínio argumentativo, chegando à conclusão devidamente fundamentada.

Difere-se, por exemplo, do obter dictum, que corresponde à parcela da fundamentação e motivação do julgamento que contém argumentos marginais, prescindíveis para o efetivo deslinde da controvérsia e proposição de solução do problema.

Considerando a sua própria natureza e a constante modificação do sistema normativo, os precedentes são, necessariamente, dinâmicos. Essa dinâmica permite situações em que o precedente deve ser modificado total ou parcialmente. É possível, ainda, uma terceira possibilidade, consistente na não aplicação do precedente em determinados casos. 
Nesse sentido, foram criadas técnicas específicas como a distinção (distinguish), superação total (overrruling) ou parcial (overriding). São técnicas fundamentais para atualização e manutenção dos precedentes enquanto ferramenta de solução de conflitos. Nos dizeres de DIDIER, BRAGA e OLIVEIRA, há distinguish:

quando houver distinção entre o caso concreto (em julgamento) e o paradigma, seja porque há divergência entre os fatos fundamentais e capitais e aqueles que serviram de base à ratio decidendi (tese jurídica), seja porque, a despeito de existir uma aproximação entre eles, alguma peculiaridade no caso em julgamento afasta a aplicação do precedente. (2010, p. 393)

Já overruling é "técnica através da qual um precedente perde sua força vinculante e é substituído (overruled) por um outro precedente.” (2010, p. 394). Overriding, por sua vez, é quando o tribunal apenas limita o âmbito de incidência de um precedente, em função da superveniência de uma regra ou um princípio legal. No overriding "não há superação total do precedente, mas apenas uma superação parcial." (2010, p. 395).

Dessa forma, diante da constatação de que o caso concreto, sob análise do Juízo, pode ser submetido a determinado precedente, o juiz deverá analisar o caso que deu origem ao mesmo. Caso não haja a necessária adequação, estar-se-á diante do distinguish. Amoldandose ao escopo fático, o juiz poderá aplicar o precedente ou superá-lo. Independentemente da conclusão do magistrado a respeito da aplicabilidade ou não do precedente, a decisão deverá, necessariamente, ser fundamentada.

Essa precaução do legislador com a necessidade de fundamentação da decisão demonstra que mesmo em sistemas jurídicos que vinculam o magistrado aos precedentes, ainda assim remanesce certo grau de liberdade interpretativa na atividade judicial. $O$ desenquadramento do caso concreto ao precedente existente exigirá do magistrado, por consequência, certo esforço argumentativo, no sentido de demonstrar, de forma pujante, a divergência ou necessidade de modificação daquele precedente.

Dessa forma, o precedente judicial representa robusto instrumento de promoção da segurança jurídica, por meio da criação de razões generalizáveis. Razões essas que deverão ser devidamente fundamentadas e cuja construção permite a vinculação lógica/argumentativa do aplicador.

Entretanto, o precedente não constitui instrumento que permite ao aplicador transportar sua obrigação de fundamentação da decisão para o próprio precedente. Em outras 
palavras, ainda que se valha ou não do entendimento firmado no precedente, é dever do aplicador fundamentar as razões que o levaram a aplicá-lo ou não.

\section{Os precedentes no sistema jurídico brasileiro}

Como apontado anteriormente, o sistema brasileiro é, historicamente, constituído pela tradição do modelo romano-germânico, no qual as regras escritas possuem prevalência sobre as demais fontes do direito. Entretanto, diante da necessidade de promover soluções para os problemas cotidianos vividos pelo Poder Judiciário e pelos jurisdicionados, sobretudo pela postura argumentativa dos aplicadores do Direito no Brasil, verifica-se a gradual valorização dos precedentes judiciais no país.

Basicamente, no modelo do civil law os julgadores devem agir de acordo com a lei, enquanto regra jurídica formalmente posta em texto. Logo, casos que guardem semelhança fática e lógico/argumentativa devem possuir a mesma resposta jurisdicional.

Ocorre que a despeito dessa expectativa, diante da liberdade de convencimento que o julgador possui e das próprias características sociais e demográficas do país, em diversas oportunidades os mesmos casos recebem decisões distintas. Isso gera imprevisibilidade, violação à isonomia e ao princípio da segurança jurídica.

Logo, além da instituição do sistema de precedentes no Brasil, foi necessário conferir a devida força vinculante a eles, sob pena de serem esvaziadas as pretensões de uniformizar o entendimento a respeito de determinados temas.

Analisando o histórico jurídico nacional a médio prazo, percebe-se que foram promovidas inúmeras mudanças na legislação processual, tanto por meio da Constituição de 1988, quanto pela legislação infraconstitucional, com o fito de institucionalizar, paulatinamente, o sistema de precedentes no Brasil.

Após a criação do Superior Tribunal de Justiça - STJ, foi publicada a Lei n. 8.038/1990, que conferiu aos seus ministros relatores e aos do Supremo Tribunal Federal STF poderes para, monocraticamente, dar e negar seguimento a recursos com base em entendimento firmado em súmula desses tribunais. Esses poderes também foram posteriormente conferidos aos desembargadores pela Lei n. 9.139/1995.

Com o advento da Lei n. 9.756/1998, a possibilidade de dar ou negar seguimento monocrático, pelos desembargadores relatores, também foi ampliada para as situações em que 
os recursos estavam em consonância ou contrariedade com a jurisprudência dominante ou súmula do respectivo tribunal, STJ ou STF.

A Emenda Constitucional n. 03/1993, por sua vez, criou a figura da Ação Declaratória de Constitucionalidade, atribuindo à decisão final a eficácia geral e o efeito vinculante aos demais Tribunais, respectivos julgadores e ao Poder Executivo. Essa mesma eficácia foi atribuída à Ação Declaratória de Inconstitucionalidade e às Arguições de Descumprimento de Preceito Fundamental, pelas Leis n. 9.868/1999 e n. 9.882/1999, respectivamente.

Na sequência, foi publicada a Emenda Constitucional n. 45/2004, que alterou o regime jurídico do efeito vinculante das decisões de mérito proferidas em Ação Declaratória de Constitucionalidade. Referido dispositivo alargou seu alcance para os demais órgãos do Poder Judiciário e da Administração Pública direta e indireta, nas esferas federal, estadual e municipal. Ademais, criou o instrumento da Súmula Vinculante do STF, com os mesmos efeitos de aplicação obrigatória.

Nesse mesmo sentido foram realizadas significativas modificações no Código de Processo Civil de 1973, por meio das Leis n. 10.352/2001, n. 11.276/2006 e n. 11.277/2006. As alterações, respectivamente, foram as seguintes: (i) a sentença fundada em jurisprudência do plenário ou súmula do STF não estaria mais sujeita ao reexame necessário; (ii) o magistrado não receberia o Recurso de Apelação quando a sentença estivesse em conformidade com súmula do STJ ou do STF e; (iii), na hipótese em que a matéria controvertida fosse unicamente de direito e já houvesse sido proferida sentença de total improcedência em casos idênticos, o juiz poderia dispensar a citação e proferir imediatamente a decisão de mérito, reproduzindo os termos daquelas anteriormente existentes.

As Leis n. 11.418/2006 e n. 11.472/2008 alteraram o Código de Processo Civil de 1973 para inaugurar a sistemática da denominada tutela pluri-individual no STF (repercussão geral) e no STJ (recursos repetitivos). Tal técnica consiste no julgamento de casos repetitivos mediante a eleição e apreciação de um caso representativo da controvérsia (leading case). $\mathrm{O}$ entendimento desses Tribunais sobre a matéria seria, então, aplicado aos demais casos idênticos, que permanecem sobrestados na origem.

A evolução do sistema de precedentes no Brasil ganhou novo e importante capítulo com o advento do Código de Processo Civil de 2015, que criou importantes instrumentos nesse sentido. Cite-se, por exemplo, a criação do Incidente de Resolução de Demandas 
Repetitivas (IRDR), sob inspiração do instrumento jurídico alemão (Musterverfahren), que trouxe nova disciplina processual ao determinar que devem ser observadas as decisões nele proferidas, bem como em Recursos Especiais e Extraordinários representativos de controvérsia.

Para tanto, foi previsto o instrumento da reclamação, que visa garantir a prevalência e aplicabilidade do entendimento firmado. Segundo SOUZA, a reclamação constitucional possui natureza jurídica de ação autônoma. Assim a reclamação não é recurso nem mero incidente processual, mas sim "processo independente, instaurado por força do exercício de ação autônoma de impugnação de estatura constitucional” (2013, p. 921). Referido autor vai além, indicando o alcance da ação reclamatória:

sob outro prisma, tanto o recurso quanto o incidente processual pressupõem a
existência de processo em curso. A reclamatória, entretanto, não depende da
existência de processo em curso. Com efeito, a reclamação pode ter lugar depois do
término do processo originário, a fim de que o respectivo julgamento seja
respeitado. Aliás, a reclamação pode ter lugar até mesmo sem a existência de
anterior processo. (SOUZA, 2013, p. 922).

Dessa forma, a ação reclamatória constitucional se posiciona no sistema jurídico como "verdadeira ação de garantia de direitos constitucionais, notadamente da coisa julgada, do juiz natural e do devido processo legal", o que demonstra ser manifesta garantia constitucional, similar ao Mandado de Segurança (SOUZA, 2013, p. 924). BERNARDES e COSTA CONTIJO, ao tratar da reclamatória constitucional, afirmam que "em primeiro lugar pode-se extrair da própria Constituição Federal de 1988 as linhas deontológicas do sistema de precedentes em nosso ordenamento" $(2018,133)$.

Considerando que os sistemas dos recursos repetitivos (STJ), repercussão geral (STF) e das súmulas vinculantes fatalmente resultaram em melhora do ambiente de instabilidade jurídica, estes foram mantidos com o advento do Código de Processo de Civil de 2015.

As referidas modificações não representam completa ruptura do modelo civil law por parte do ordenamento jurídico brasileiro, atribuindo forma vinculante aos precedentes, de modo que em análise rápida e pouco cuidadosa poderia se dizer que estar-se-ia diante do modelo common law.

Com efeito, o sistema de precedentes brasileiro possui algumas características que o distingue dos demais. Parte da doutrina aponta que "o nosso precedente nasce de um único 
julgamento, ao passo que no common law nasce da reiteração de posicionamentos" (GONÇALVES, 2015, p. 244).

Percebe-se, portanto, que o sistema jurídico brasileiro acabou por instituir a sistemática de precedentes judiciais de forma particular, considerando as especificidades e características do seu próprio sistema. Pretendeu-se propor uma solução para um cenário específico existente, adaptando as características dos modelos do civil law e do common law "à brasileira".

\title{
4. Da sistemática dos precedentes no Código de Processo Civil de 2015
}

Com o advento do CPC/2015, foi instituído o denominado microssistema de precedentes no Brasil. A sua finalidade é concretizar princípios fundamentais como o da segurança jurídica, por meio da calculabilidade e previsibilidade, isonomia, economia processual e duração razoável do processo. Ao tratar sobre a necessidade de calculabilidade e previsibilidade do sistema jurídico, enquanto revelação do próprio princípio da segurança jurídica, Humberto Ávila ensina:

\begin{abstract}
Existe um estado de calculabilidade do Direito quando o cidadão tem, em grande medida, a capacidade de antecipar e de medir o espectro reduzido e pouco variável de consequências atribuíveis abstratamente a atos, próprios e alheios, ou a fatos e o espectro reduzido de tempo dentro do qual a consequência definitiva será aplicada. A exigência de calculabilidade, portanto, não impede mudanças. Ela apenas é contrária a um tipo de mudança que fuja do espectro material e temporal de consequências antecipáveis pelo contribuinte e que termine por frustrar a confiança daqueles que, com apoio nas normas jurídicas então em vigor, tomaram decisões, adotaram condutas, optaram por um tipo de negócio, e assim por diante - como pontifica Carraza.

Navarro Coelho esclarece com exatidão o argumento: "Que as mutações sejam inevitáveis, ninguém duvida. O que se pretende, porém, é que não sejam tumultuárias e nada convincentes, pois precisam guardar respeito aos princípios diretores do sistema jurídico, ser razoáveis e dotadas de racionalidade (ratio)" (Ávila, 2012, p. 603/604).
\end{abstract}

Logo, é dever do sistema jurídico garantir que o jurisdicionado, em demandas que já tiveram a devida análise pelo Poder Judiciário, possa identificar e calcular qual será a resposta que terá para a sua demanda judicial. Viola a própria segurança jurídica a situação em que o jurisdicionado fique à mercê de verdadeira loteria jurídica, fazendo com que o sistema de distribuição por sorteio dos processos traduza a possibilidade e probabilidade de vencer ou perder sua demanda.

Revista de Direito Tributário e Financeiro | e-ISSN: 2526-0138 | Belém | v. 5 | n. 2 | p. 37 - 58 | Jul/Dez. 2019. 
A garantia de entendimentos jurisprudenciais uniformes gera maior previsibilidade do direito e, por conclusão lógica, maior segurança jurídica. Relativamente ao princípio da isonomia, WAMBIER e DANTAS afirmam que é "inútil a lei ser a mesma para todos, se os tribunais podem interpretá-la de modos diferentes e surpreender os jurisdicionados" (2016, p. 179).

De fato, a existência de norma jurídica geral e abstrata, aplicável em igual medida e proporção aos jurisdicionados, cuja interpretação distinta foi aplicada por diferentes julgadores, ofende o princípio da isonomia.

Igualmente deve ser garantido o princípio da duração razoável do processo e da economia processual, enquanto corolário do disposto no inciso LXXVIII, do artigo $5^{\circ}$, da Constituição de 1988. Nesse sentido, vale a velha máxima, bem traduzida por THEODORO JÚNIOR: “justiça tardonha não é justiça, mas pura e deplorável injustiça” (2016, p. 48).

Parte da doutrina ainda elenca outros princípios como fundamentais e norteadores do sistema de precedentes no Brasil. DERZI, ao tratar do denominado princípio da praticidade, afirma que se trata de "argumento pragmático, segundo o qual a superlotação do Poder Judiciário torna inviável a administração da justiça se não houver a vinculação" (2017, p. 122).

Com base nesses princípios, foi inserido o art. 926 no Código de Processo Civil de 2015, que estabelece a necessidade de os Tribunais manterem a jurisprudência atualizada, uniformizada, estável e coerente. MASSARA afirma que:

\begin{abstract}
A coerência seria a reprodução de uma linha de raciocínio anterior. A integridade, por sua vez, seria um conceito mais amplo, pois exigiria um comportamento adequado não só a linha de julgados prévios, exigindo uma harmonização principiológica, passando pela Constituição de 1988, leis e regulamentos. Já a estabilidade seria o compromisso de não alteração da linha de raciocínio adotada, a não ser que haja razões eficientes para tanto, como mudança de lei, distinção fática substancial, dentre outros. (2018, p. 175)
\end{abstract}

DWORKIN, ao tratar da integridade enquanto elemento substancialmente importante, ensina que:

A integridade exige que as normas públicas da comunidade sejam criadas e vistas, na medida do possível, de modo a expressar um sistema único e coerente de justiça e equidade na correta proporção. Uma instituição que aceite esse ideal às vezes irá, por esta razão, de estreita linha das decisões anteriores, em busca de uma fidelidade 
aos princípios concebidos como mais fundamentais a esse sistema como um todo. (2005, p. 263)

A partir dessa moldura, parte da doutrina entende que o sistema de precedentes no Brasil não decorreria de imposição legal, “mas em razão de apresentar uma nova solução hermenêutica com essa harmonia principiológica existente no sistema jurídico como um todo, desde a Constituição Federal de 1988” (MASSARA, 2018, p. 176).

Não se comunga desse entendimento. O sistema de precedentes no Brasil, de fato, decorre da necessidade de se valer de soluções hermenêuticas para os problemas existentes no cenário jurídico nacional. Entretanto, decorre de substancial e bem definida imposição legal, conforme apontado nos tópicos anteriores e evidenciada por meio do artigo 926 e seguintes do Código de Processo Civil de 2015.

Referido artigo visa concretizar a cultura que já vinha se formando no cenário jurídico brasileiro, no sentido de estabelecer a valorização dos precedentes, inserindo-se no contexto de conferir maior vinculabilidade, de modo argumentativo, mas impositivo, às decisões paradigmáticas dos tribunais.

Neste mesmo sentido seguem as regras e o comando extraídos do artigo 927, do Código de Processo Civil de 2015. Referido dispositivo visa implementar nova política judiciária delineada pelo artigo 926 do mesmo diploma, trazendo a imperatividade de observância das decisões judiciais indicadas em seus incisos. Os parágrafos cuidam de veicular regramento específico sobre a formação, aplicação, não aplicação ou superação dos julgados. LOPES FILHO ressalta o acerto terminológico da expressão "observados":

\footnotetext{
Isso é importante porque observar equivale a atentar e analisar e se contrapõe a ignorar, desconsiderar ou desconhecer. Ou seja, o julgador não teria a obrigação inarredável de reproduzir o mesmo entendimento de um precedente, mas não poderia julgar como se não existisse. (2016, p. 275).
}

Os precedentes elencados no artigo 927, do Código de Processo Civil de 2015, são vinculantes, especialmente aqueles previstos no inciso III, uma vez que ensejam reclamação. Nesse mesmo sentido segue parcela da doutrina, como se observa do posicionamento de WAMBIER e DANTAS (2016, p. 179), que se alinham ao mesmo entendimento.

Entretanto, tal entendimento não é unânime. BUENO afirma que a decisão jurisdicional no sistema brasileiro "depende de prévia autorização constitucional - tal qual a feita pela Emenda Constitucional n 45/2004 - e, portanto, fora da esfera de disponibilidade do 
legislador infraconstitucional", reforçando, ainda, que "a tradição do direito brasileiro não é de common law". (2017, p. 568)

Considerando o sistema normativo atualmente posto, os precedentes previstos no artigo 927 possuem vinculação tanto a partir da ótica legal, por imposição de regra jurídica, quanto na ótica lógico/argumentativa. Conforme apontado anteriormente, essa vinculabilidade é resultado da própria necessidade de consagração dos princípios da segurança jurídica, isonomia, duração razoável do processo e economia processual.

\section{Reflexo do sistema de precedentes nas lides judiciais tributárias}

A instituição de um novo sistema de precedentes no cenário processual brasileiro tende a produzir um efeito geral, atingindo todas as áreas do Direito. Entretanto, não se pode ignorar o fato de que determinadas áreas específicas podem ser atingidas em maior ou menor grau, a depender das suas características próprias e inerentes.

No âmbito do Direito Tributário, a instituição do sistema de precedentes tende a causar impactos relevantes, como aponta GODOI:

\footnotetext{
Na matéria tributária, o mais comum é que a questão debatida no caso tenha aptidão para atingir milhares ou milhões de contribuintes que se encontram em situação idêntica ou semelhante ao do recorrente/recorrido, o que resulta no reconhecimento de existência de grande impacto econômico-social na discussão. (2016, p. 64)
}

Em análise percentual, o ramo do Direito Tributário é o que mais possui discussões sobre a existência de repercussões gerais no âmbito do STF, respondendo por $26 \%$ dos temas. Levando em conta as próprias características do âmbito tributário, uma vez que discussões dessa natureza tendem a ter largo alcance, atingindo inúmeros contribuintes e envolvendo grandes valores, o sistema de precedentes demonstra ser instrumento de relevante impacto para o Direito Tributário.

A alta complexidade do sistema tributário brasileiro é assunto comum e de pública notoriedade em razão das inúmeras leis, decretos, regulamentos, instruções normativas, portarias e outras regras que regulam a matéria. Esse cipoal de normas resulta em incertezas interpretativas, resultando na divergência de entendimento que, naturalmente, serão dirimidas pelo Poder Judiciário. 
WAMBIER e DANTAS apontam algumas discussões que demonstram a instabilidade interpretativa instalada no âmbito tributário: (i) divergência entre o STF e STJ a respeito da isenção de Cofins para sociedades civis de prestação de serviços profissionais, que resultou no cancelamento da súmula 276, do STJ; (ii) ICMS sobre habilitação de telefonia, matéria em que o STJ se manifestou em recurso repetitivo pela não incidência e o STF modificou seu posicionamento a respeito da inexistência da matéria constitucional, vindo a, posteriormente, analisar o tema; (iii) possibilidade de apropriação de créditos de IPI sobre a aquisição de insumos isentos ou sujeitos à alíquota zero, em que o STF sempre se posicionou favoravelmente aos contribuintes e, em 2007, sem promover o devido overrruling, modificou esta orientação (2016, p. 183/184).

Poder-se-ia, ainda, citar outros exemplos de instabilidade no âmbito tributário. Um deles seria a discussão relativa à inclusão do ICMS na base de cálculo das contribuições ao PIS e Cofins, na qual o STJ possuía as súmulas n. 68 e n. 94, desfavoráveis aos contribuintes e o STF, décadas após, se manifestou pela inconstitucionalidade da inclusão. Igualmente, a discussão a respeito da incidência de IRPJ e CSLL sobre a Selic na repetição de indébito, em que o STJ historicamente possui entendimento desfavorável aos contribuintes, enquanto o STF se posicionava pela ausência de repercussão geral; no entanto, a Corte Constitucional agora reconheceu a relevância da matéria sob seu prisma de atuação.

É diante desse contexto que o sistema de precedentes possui especial relevância em matéria tributária, como forma de estabilizar interesses e promover a devida calculabilidade do Direito.

Não se pode olvidar que as Execuções Fiscais hoje representam um terço dos processos em tramitação no Brasil. Isso significa que estabelecer razões generalizáveis, aplicáveis às inúmeras ações em comento, tem o condão de reduzir de modo significativo a pressão existente sobre o Poder Judiciário, isto considerando sua eficácia e a coerência na aplicação do sistema jurídico.

O impacto dos precedentes judiciais nas demandas tributárias não decorre da sua análise estritamente em relação aos processos judiciais. Há que se analisar o seu impacto no Procedimento Tributário Administrativo, tendo em vista que esta é, em regra, frase preliminar que pode resultar em processos judiciais, seja por meio de Ação Anulatória ou ordinária, seja por meio de Execução Fiscal e respectivos Embargos. 


\section{Vinculação do procedimento tributário administrativo aos precedentes judiciais}

No âmbito do Processo Tributário, tem-se verificado a divergência substancial entre as orientações e entendimento firmados nos Procedimentos Tributários Administrativos e aquelas aplicadas, de modo reiterado e sistemático, pelo Poder Judiciário.

Como observado por MASSARA, um dos emblemáticos exemplos a respeito dessa substancial divergência pode ser demonstrado a partir da discussão a respeito da Súmula n. 116 do STJ, que contém enunciado no sentido de que "não constitui fato gerador do ICMS o simples deslocamento de mercadoria de um para outro estabelecimento do mesmo contribuinte". Ocorre que essa orientação continua sendo ignorada pelos Estados, que corriqueiramente promovem autuações que serão, fatalmente, canceladas pelo Poder Judiciário (2018, p. 182).

No ano de 2016 houve importante e relevante avanço no sentido de conferir maior vinculabilidade das decisões judiciais ao Procedimento Tributário Administrativo, com a edição da Portaria n. 152, do Ministério da Fazenda, que alterou o Regimento Interno do Conselho Administrativo de Recursos Fiscais (CARF) para inserir a necessidade de observância dos recursos repetitivos dos Tribunais Superiores pelo órgão administrativo.

Nesse mesmo sentido, o Código de Processo Civil de 2015 promoveu importante inovação, ao dispor em seu artigo 15 que na ausência de normas que regulem os procedimentos administrativos, o CPC será aplicado de forma supletiva e subsidiária. É importante observar, portanto, que o legislador definiu o alcance de aplicação do CPC no procedimento administrativo, limitando suas hipóteses ao caso de lacunas e quando for necessária a complementação da regra processual administrativa.

Ademais, iniciou-se um debate a respeito da aplicação dos artigos 926 e 927 aos julgadores administrativos. Estariam tais julgadores sujeitos às regras de vinculação de observação aos precedentes judiciais que tratem da mesma matéria? MACHADO (2017, p. 247) e MELO (2017, p. 495) entendem que o artigo 927 não vincula os julgadores administrativos, sendo inaplicável ao Procedimento Tributário Administrativo, uma vez que referida regra trata apenas da hipótese de juízes e tribunais.

Quando o legislador pretendeu vincular o julgador administrativo, o fez de forma expressa, como nos casos de súmulas vinculantes e do controle concentrado de constitucionalidade. Assim, o artigo 927 não seria aplicável aos Procedimentos Tributários 
Administrativos nem subsidiariamente nem supletivamente, salvo nos casos citados anteriormente.

OLIVEIRA, SOUZA e BARBOSA também possuem entendimento no sentido da inaplicabilidade do artigo 927 do CPC/2015. Ressaltam, entretanto, a legitimidade da possibilidade de que "as leis especiais que regem os processos administrativos preverem tal vinculação" (2017, p. 368/370), tal como ocorre no âmbito do CARF, como citado anteriormente.

Comunga-se desse mesmo entendimento. Diante do silêncio da Constituição, a determinação de observância obrigatória dos precedentes estaria calcada no âmbito da competência de cada ente federativo. Dessa forma, não poderia o intérprete conferir largo alcance ao teor do artigo 927, a ponto de impor, por analogia, ao julgador administrativo a observância das decisões que não tenham eficácia vinculante para a Administração Púbica.

Ademais, o artigo 15, do CPC/2015, não é aplicável, uma vez que não há lacuna a ser colmatada, mas apenas opção do próprio legislador em razão do seu silêncio eloquente, que constitui legítima manifestação de vontade. Lado outro, não se pode ignorar a existência de doutrina em sentido contrário.

MASSARA se posiciona no sentido de que o legislador pretende estabelecer uma Teoria Geral do Processo, aplicável não somente ao processo judicial, mas também ao próprio procedimento administrativo. Segundo o autor, a interpretação do artigo 927, do CPC/2015 "não pode se prender à mera literalidade do texto legal ou a uma interpretação míope da separação de poderes", uma vez que o ordenamento jurídico brasileiro busca a integridade do direito, “que é justamente o que o sistema de precedentes visa concretizar". (2018, p. 183). BELCHIOR, SILVEIRA e AMARAL também afirmam que:

\footnotetext{
O dever de proporcionar unidade ao Direito e uniformidade à jurisprudência também deve ser invocado no processo administrativo fiscal, já que busca tutelar a segurança jurídica também no processo administrativo, assegurando maior previsibilidade das decisões e igualdade entre os cidadãos e ao Direito, como um todo. (2017, p. 59)
}

MELLO, LUSTOSA e SIMÕES vão além, afirmando que os precedentes judiciais não se aplicam somente aos julgadores administrativos, mas também aos órgãos de fiscalização de Procuradorias, que “devem se curvar às orientações emanadas pelo STJ e pelo STF (...) visando à segurança jurídica, à moralidade e à eficiência da Administração Pública, à legalidade, confiança legítima e isonomia” (2017, p. 424). 
Não se ignora que o posicionamento dos autores possui relevante substância e importância para a discussão. De fato, nos parece pouco lógico e razoável a situação em que o julgador administrativo irá validar a cobrança de determinado crédito de tributo que, fatalmente, será cancelado pelo Poder Judiciário.

A perpetuação de discussões tributárias dessa natureza não representa ganho ao Fisco, uma vez que não traduzem qualquer retorno financeiro, diante do seu iminente cancelamento. Na realidade, representará custo desnecessário, uma vez que o ente será compelido a suportar o pagamento de honorários sucumbenciais e despesas processuais.

Além disso, representa expressivo custo para o contribuinte, que deverá contratar advogado, garantir o débito, seja por meio de depósito judicial da quantia integral, segurogarantia ou quaisquer outras hipóteses previstas na legislação, e aguardar o deslinde final da demanda.

Ainda que se esteja diante desse cenário indesejado, a medida proposta pelos autores não encontra respaldo no próprio ordenamento jurídico brasileiro. Principalmente nas regras que tratam do precedente judicial, do seu alcance e dos órgãos que estão a ele vinculados.

Dessa forma, entende-se que os precedentes judiciais não se aplicam automaticamente aos Procedimentos Tributários Administrativos, sendo que a medida necessária é a modificação dos respectivos regramentos que tratam dos processos administrativos de cada ente, assim como fez o CARF.

Essa modificação deve ser feita em benefício do próprio ente federativo, de modo a reduzir os custos indevidos e desnecessários com a cobrança de valores que, certamente, não prosperarão no âmbito do Poder Judiciário.

\section{Posicionamento do CARF a respeito da exclusão do ICMS da base de cálculo do PIS e Cofins}

O Conselho Administrativo de Recursos Fiscais (CARF) promoveu a devida alteração em seu regimento interno, passando a prever a necessidade de reprodução das decisões definitivas de mérito proferidas pelo STF e STJ, sob a sistemática dos recursos representativos de controvérsias. 
$\mathrm{O}$ art. $62, \S 2^{\circ}$, do Regime Interno do CARF aparentemente solucionaria, pelo menos no âmbito daquele tribunal administrativo, as discussões a respeito da vinculação dos precedentes aos julgadores administrativos.

Ocorre que o julgamento do RE n. 574.706/PR inaugurou uma nova problemática a respeito do tema. No referido Recurso Extraordinário, o STF firmou a tese de que o ICMS não pode ser incluído na base de cálculo do PIS e Cofins.

Referida decisão foi objeto de Embargos de Declaração por parte da União, que pretende discutir aspectos relativos ao alcance da decisão, por meio da possibilidade de sua modulação, e sobre o valor a ser excluído, se seria o valor pago ou destacado no respectivo documento fiscal.

Independentemente do deslinde do recurso de embargos de declaração, fato é que o STF já consolidou, de forma definitiva, o posicionamento no sentido da inconstitucionalidade da inclusão do imposto estadual na base de cálculo das supracitadas contribuições. Dessa forma, esse fato atrairia a aplicação do artigo $62, \S 2^{\circ}$, do Regimento Interno do CARF.

Ocorre que no âmbito daquele Conselho a norma que buscaria dar coesão, coerência e unicidade à jurisprudência acabou, inusitadamente, resultando em nova divergência. Parte do CARF passou a entender que a referida decisão ainda não possui a necessária definitividade, em razão da possibilidade de modificação, ainda que parcial, dos seus termos, diante da oposição dos Embargos de Declaração.

Segundo esses julgadores deveria prevalecer o até então existente julgamento definitivo sobre a matéria, consubstanciado no Recurso Especial n. 1.144.469/PR, julgado pelo STJ sob a sistemática dos recursos repetitivos, em que restou definido que é possível incluir o ICMS na base de cálculo do PIS e Cofins:

PIS/COFINS. BASE DE CÁLCULO. INCLUSÃO DO ICMS. RECURSO REPETITIVO. STJ. TRÂNSITO EM JULGADO. CARF. REGIMENTO INTERNO.

Em 13.03.2017 transitou em julgado o Recurso Especial no 11444669/PR, proferido pelo STJ sob a sistemática do art. 543-C do CPC/73, que firmou a seguinte tese: "O valor do ICMS, destacado na nota, devido e recolhido pela empresa compõe seu faturamento, submetendo-se à tributação pelas contribuições ao PIS/PASEP e COFINS, sendo integrante também do conceito maior de receita bruta, base de cálculo das referidas exações", a qual deve ser reproduzida nos julgamentos do CARF a teor do seu Regimento Interno.

Em que pese o Supremo Tribunal Federal ter decidido em sentido contrário no Recurso Extraordinário $\mathrm{n}^{\circ} 574.706$ com repercussão geral, publicado no DJE em 02.10.2017, como ainda não se trata da decisão definitiva a que se refere o art. 62, $\S 2^{\circ}$ do Anexo II do Regimento Interno do CARF, não é o caso de aplicação

Revista de Direito Tributário e Financeiro | e-ISSN: 2526-0138 | Belém | v. 5 | n. 2 | p. 37 - 58 | Jul/Dez. 2019. 
obrigatória desse precedente ao caso concreto.

Recurso Voluntário negado.

(CARF, $3^{\mathrm{a}}$ Seção $/ 4^{\mathrm{a}}$ Câmara $/ 2^{\mathrm{a}}$ Turma Ordinária, Recurso Voluntário, Rel. Waldir Navarro Bezerra, Acórdão no 3402-006.283, julg. 26.02.2019)

Esse posicionamento não é unânime no âmbito do mencionado Conselho, sendo que existem julgados em sentido diametralmente oposto, qual seja, no sentido de aplicar a nova orientação firmada pelo STF:

ASSUNTO: CONTRIBUIÇÃO PARA O FINANCIAMENTO DA SEGURIDADE SOCIAL (COFINS)

Data do fato gerador: $15 / 07 / 2005$

INCLUSÃO DO ICMS E DO ISS NA BASE DE CÁLCULO DO PIS E DA COFINS. IMPOSSIBILIDADE.

O ICMS e o ISS não compõem a base de cálculo do PIS/COFINS, conforme pacificado pelo Supremo Tribunal Federal no julgamento do RE n ${ }^{\circ} 574.706$, aplicável analogamente ao presente caso.

(CARF, $3^{\mathrm{a}}$ Seção/ $3^{\mathrm{a}}$ Câmara/ $2^{\mathrm{a}}$ Turma Ordinária, Recurso Voluntário, Rel. Paulo Guilherme Deroulede, Acórdão nº 3302-007.132, julg. 25.05.2019)

Passou a existir, no âmbito do CARF, dois posicionamentos distintos, um pela aplicabilidade da nova orientação firmada pelo STF e outro pela sua temporária inaplicabilidade, enquanto pendente o julgamento dos Embargos de Declaração.

Posiciona-se neste trabalho no sentido de reconhecer que a orientação do STF no sentido da inconstitucionalidade da inclusão do ICMS na base de cálculo do PIS e Cofins já deve ser reproduzido pelo órgão administrativo. O julgamento pendente, considerando os próprios termos dos Embargos de Declaração opostos, não terá o condão de modificar o entendimento firmado pela Corte, mas de definir sua base de cálculo exata e a modulação de seus efeitos.

A justificativa jurídica utilizada pela inaplicabilidade não encontra respaldo fático quando confrontada com o próprio teor dos argumentos que estão pendentes de apreciação. Havendo julgamento definitivo do mérito, não há que se falar em necessidade de aguardar o julgamento dos aclaratórios, de modo a autorizar que o tribunal administrativo permaneça reproduzindo decisões em confronto com a orientação da Suprema Corte.

Dessa forma, em atenção ao disposto no art. $62, \S 2^{\mathrm{a}}$, do Regimento Interno do CARF, a orientação firmada pelo STF no RE n. 574.706/PR deve ser imediatamente aplicada aos Procedimentos Tributários Administrativos, sob pena de violação ao próprio Regimento Interno e ao sistema de precedentes instituído no ordenamento jurídico brasileiro. 


\section{Conclusão}

O presente trabalho pretendeu demonstrar, sem esgotar o tema, sobre a relevância dos precedentes judiciais para o sistema jurídico em que aplicado. Chama a atenção o fato de que os precedentes judiciais, diante da própria necessidade de criação de ferramentas para a solução de problemas existentes, passam a ultrapassar a sua esfera específica decorrente do modelo do common law, passando a dialogar, dentro dos limites possíveis, com sistemas jurídicos que adotam a matriz do civil law.

No Brasil, seu ápice veio com o advento do Código de Processo Civil de 2015, que inaugurou verdadeiro microssistema de precedentes no Brasil, instituindo regras de aplicação claras e bem definidas.

A despeito dos significativos avanços que referido microssistema trouxe, entende-se que os precedentes judiciais são automaticamente inaplicáveis aos Procedimentos Tributários Administrativos. A sua força vinculante demanda, necessariamente, a modificação dos respectivos dispositivos dos entes federativos, sob pena de violação às regras constitucionais.

Como todo novo instituto criado demanda análise, conhecimento, estudo e maturação, parece-nos que os precedentes judiciais ainda possuem amplo caminho a ser percorrido, especialmente pela necessidade de se delimitar os aspectos de sua utilização num sistema jurídico moldado no âmbito do modelo romano-germânico.

Cita-se, como exemplo, a necessidade de adequação dos respectivos diplomas jurídicos de cada um dos entes federativos no sentido de garantir a aplicação dos precedentes judiciais ao Procedimento Tributário Administrativo respectivo, objetivando evitar a discussão no tocante à sua aplicabilidade. Essa modificação representa ganho para todos os lados, conforme demonstrado ao longo do texto.

Outro ponto que demanda maturação a respeito dos precedentes judiciais consiste na necessidade de maior compreensão sobre o início da sua aplicabilidade. Como apontado, o dispositivo que deveria garantir maior segurança e unicidade no CARF acabou, de modo inesperado, resultando em nova divergência naquele tribunal violando a isonomia, segurança jurídica e calculabilidade do direito.

Exatamente neste contexto que se utilizou a análise doutrinária desenvolvida ao caso concreto da inclusão do ICMS na base de cálculo das contribuições do PIS e da COFINS, 
justamente no âmbito do mencionado Conselho de Recursos, que incorporou em seu regramento interno os precedentes judiciais relativos às questões tributárias federais.

Logo, entende-se que, como forma de garantir a efetividade dos precedentes judiciais no Brasil, é necessário que se enfrente tal matéria, definindo, de modo claro, a partir de qual momento a Administração Pública estará sujeita ao entendimento firmado pelo Poder Judiciário.

\section{Referências Bibliográficas}

BELCHIOR, Déborah Sales; SILVEIRA, Larissa de Castro; AMARAL, Felipe Silveira Gurgel do. O Processo Tributário e o Código de Processo Civil/2015, In MACHADO, Hugo de Brito (coord.). O Processo Tributário e o CPC/2015. São Paulo: Ed. Malheiros, 2017

BERNARDES, Flávio Couto. O aspecto procedimental como elemento da norma jurídica tributária e seus reflexos na formação do título executivo. Tese de doutorado. Biblioteca da Universidade Federal de Minas Gerais, 2006. Disponível em: < http://www.bibliotecadigital.ufmg.br/dspace/handle/1843/BUBD-96ZKBJ>.

BERNARDES, Flávio Couto; COSTA GONTIJO, Pedro Augusto. A eficácia vinculante dos precedentes sobre o processo administrativo tributário. In: RIBEIRO, Rodrigo de Araújo e outros (Org). Advocacia Pública em Juízo. Belo Horizonte:Editora D’Plácido, 2018.

BERNARDES, Flávio Couto; PIMENTA, Victor Pimenta de. Jurisprudência Constitucional da Katchanga. Revista da Faculdade Mineira de Direito, v. 21, n. 42, 2018.

BUENO, Cassio Scarpinella. Novo Código de Processo Civil Anotado. $3^{\text {a }}$ ed. Saraiva: São Paulo, 2017

DERZI, Misabel Abreu Machado. A proibição de se criar tributo por meio de interpretação analógica e a decisão judicial orientada por precedentes e jurisprudência consolidada. In MACHADO, Hugo de Brito (coord.). O Processo Tributário e o CPC/2015. São Paulo: Ed. Malheiros, 2017

DIDIER JR., Fredie; BRAGA, Paula Sarno; OLIVEIRA, Rafael. Curso de Direito Processual

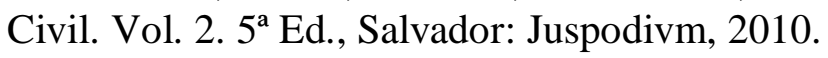

DWORKIN, Ronald. O império do direito. Tradução de Jeferson Luiz Camargo, $3^{\mathrm{a}}$ ed., São Paulo: Martins Fontes, 2014

GODOI, Marciano Seabra de. Novo Código de Processo Civil e sua normatização sobre precedentes judiciais: possíveis impactos no âmbito das lides tributárias. In HENRIQUES, Guilherme de Almeida; GODOI, Marciano Seabra de; BONITO, Rafhael Frattari; LOBATO, Valter de Souza (Coords.). Os impactos do Novo CPC sobre o Processo Judicial Tributário. Belo Horizonte: Editora D’Plácido, 2016

GONÇALVES, Carla de Lourdes. Precedentes Judiciais e as Razões de decidir: A importância do art. 489, $\S 1^{\circ}$, inciso V do NCPC. In CARVALHO, Paulo de Barros (coord.). Direito Tributário e os Novos Horizontes do Processo. São Paulo: Noeses, 2015

LOPES FILHO, Juraci Mourão. Os precedentes Judiciais no Constitucionalismo Brasileiro Contemporâneo. $2^{\mathrm{a}}$ ed, Salvador: Juspodivm, 2016 
MACHADO, Hugo de Brito. O processo Tributário e o Código de Processo Civil/2015. In MACHADO, Hugo de Brito (coord.). O Processo Tributário e o CPC/2015. São Paulo: Ed. Malheiros, 2017

MARCATO, Antônio Carlos. Os precedentes judiciais e o direito brasileiro. In SARRO, Luís Antônio Giampaulo (coord.). Novo código de processo civil: principais alterações no sistema processual civil. São Paulo: Rideel, 2014

MARINONI, Luiz G.; ARENHART, Sérgio C.; MITIDIERO, Daniel. Curso de Processo Civil, vol. 2, $3^{\text {a }}$ ed., São Paulo: Editora Revista dos Tribunais, 2017

MASSARA, Luiz Henrique Nery. A vinculação dos Tribunais Administrativos Fiscais aos Precedentes Judiciais. In CARDOSO, Alessandro Mendes; TEIXEIRA, Alexandre Alkmim; MASSARA, Luiz Henrique Nery; CAMPOS, Marcelo Hugo de Oliveira; CASTRO JUNIOR, Paulo Honório de (orgs.). Processo Administrativo Tributário. Belo Horizonte: Editora D’Plácido, 2018

MELLO, Gustavo Miguel de; LUSTOSA, Eduardo da Silva; SIMÕES, Luiz Carlos Marquês. Processo Tributário e o Código de Processo Civil/2015. In MACHADO, Hugo de Brito (coord.). O Processo Tributário e o CPC/2015. São Paulo: Ed. Malheiros, 2017

MELO, José Soares de. O Processo Tributário e o Código de Processo Civil/2015. In MACHADO, Hugo de Brito (coord.). O Processo Tributário e o CPC/2015. São Paulo: Ed. Malheiros, 2017

OLIVEIRA, Ricardo Mariz; SOUZA, Henrique Coutinho; BARBOSA, Marcos Engel Vieira. Processo Tributário e o Código de Processo Civil/2015. In MACHADO, Hugo de Brito (coord.). O Processo Tributário e o CPC/2015. São Paulo: Ed. Malheiros, 2017

THEODORO JR., Humberto. Normas Fundamentais. In THEODORO JR., Humberto (coord.). Processo Civil Brasileiro: novos rumos a partir do CPC/2015. Belo Horizonte: Del Rey, 2016

WAMBIER, Teresa Arruda Alvim; DANTAS, Bruno. Recurso Especial, Recurso Extraordinário e a Nova Função dos Tribunais Superiores no Direito Brasileiro. $3^{\text {a }}$ ed., São Paulo: Revista dos Tribunais, 2016

\section{Legislação}

BRASIL, Lei nº 13.105, de 16 de março de 2015. Código de Processo Civil

\section{Jurisprudência administrativa}

CARF, $3^{\text {a Seção/ }} 3^{\text {a }}$ Câmara/ $2^{\text {a }}$ Turma Ordinária, Recurso Voluntário, Rel. Paulo Guilherme Deroulede, Acórdão n ${ }^{\circ}$ 3302-007.132, julg. 25.05.2019. Consultado em carf.fazenda.gov.br (online) em 30.08.2019

CARF, $3^{\mathrm{a}}$ Seção $/ 4^{\mathrm{a}}$ Câmara $/ 2^{\mathrm{a}}$ Turma Ordinária, Recurso Voluntário, Rel. Waldir Navarro Bezerra, Acórdão $n^{\circ}$ 3402-006.283, julg. 26.02.2019. Consultado em carf.fazenda.gov.br (online) em 30.08.2019 